the Camp Ridge Quartzite indicate emergence and the development of topographic relief, and they may represent cessation of marine sedimentation and emergence of the whole area.

$$
\text { M. G. LAIRD }
$$

P. B. ANDREWS

New Zealand Geological Survey, Christchurch

\section{P. KYLE}

Geology Department

Victoria University,

Wellington

Antarctic Division,

DSIR,

Christchurch

Received April 10, 1972.

1 Dow, J. A. S., and Neall, V. E., Norg. Geol. Unders. (in the press)

2 Rastall, R. H., and Priestley, R. E., Nat. Hist. Rep. Brit. Antarct. (Terra Nova) Exped. 1910, Geol., 1, 121 (1921).

${ }^{3}$ Schuchert, C., and Cooper, G. A., Mem. Peabody Mus. Nat. Hist., 4, 49 (1932).

4 Kobayashi, T., Int. Geol. Congr., 20, 352 (1956).

5 Brown, D. A., Campbell, K. S. W., and Crook, K. A. W., The Geological Evolution of Australia and New Zealand, 67 (Pergamon Press, 1968).

6 Webers, G. F., Antarctic J., US, 5, 163 (1970).

7 Öpik, A. A., Bur. Min. Res. Aust. Bull., 64, 49 (1963).

${ }^{8}$ Palmer, A. H., Antarctic J., US, 5, 162 (1970).

9 Hill, D., Trans. Roy. Soc. NZ, 2, 137 (1964).

10 Gunn, B. M., and Warren, Guyon, NZ Geol. Surv. Bull., n.s., 71 , $56(1962)$.

${ }^{11}$ Gair, H. S., Sturm, A., Carryer, S. J., and Grindley, G. W., Geological Map of Antarctia 1:1.000,000, Antarctic Map Folio Series, sheet $13(1969) . c$

12 Faure, G., and Gair, H. S., NZ J. Geol. Geophys., 13, 1026 (1970).

13 Nathan, S., NZ J. Geol. Geophys., 14, 510 (1971).

\section{The Direct Viewing and Brief-time Recording of Crystallographic Events}

THE exposure times involved in obtaining $X$-ray diffraction patterns are an obstacle to the study of dynamic processes. Several workers have tried to devise visual presentations of the diffraction patterns from transient crystallographic events, and recently Chester and Koch ${ }^{1}$ reported some success using a vidicon tube which was sensitive to X-rays and which had a complex diode mosaic as photocathode. Other workers, including ourselves, have used a phosphor as an image converter, the visual image produced by the phosphor being amplified by a high-gain image intensifier. We have had some success with an image intensifier that has a television read-out, but the equipment is expensive, cumbersome, and has to be custom-built. Here we report that acceptable results can be obtained using relatively cheap standard night surveillance equipment currently being produced in the USA and available in the UK. These units are designed to be carried in the hand or even mounted on a rifle and are extremely compact and portable.

The 'Owl Eye' intensifier, for example, was developed by the Aerojet Delft Corporation of California for police work ${ }^{2}$. It gives a $125 \mathrm{~mm}$ diameter visual read-out which may readily be viewed by eye from a working distance of several feet and can be photographed with a standard camera. The result illustrated in Fig. 1 was obtained with this unit. X-rays from an 'Elliott GX6' generator operating at $40 \mathrm{kV}$ and $50 \mathrm{~mA}$ were emitted through a $1.5 \mathrm{~mm}$ diameter exit port to give a slightly divergent beam. The specimen consisted of a thin copper grid used as the specimen support in electron diffraction work. This was positioned directly over the exit port, the main beam being trapped by a lead stop set in a brass saddle and the diffraction pattern being transmitted via lateral cutaways.

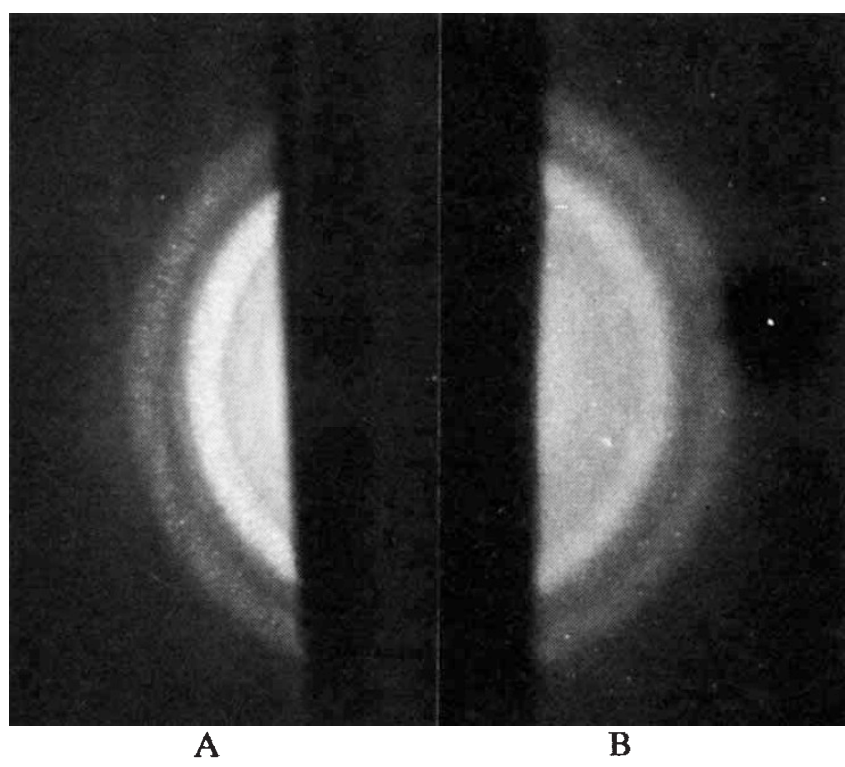

Fig. 1 Copper $\mathrm{K}$ interference pattern obtained from a polycrystalline copper specimen. $A$ was recorded directly on fast X-ray film and required an exposure of $30 \mathrm{~s}$. $B$ was obtained by photographing a visual image on the image intensifier and required an exposure of $1 / 30 \mathrm{~s}$

To use the 'Owl Eye' image intensifier the X-ray diffraction pattern was first converted into a low light level visual image. This was done with a transmission fluorescent screen obtained from the trade and consisting of a silver activated zinc/cadmium sulphide phosphor (grade YSF) of particle size 25-30 $\mu \mathrm{m}$. This is deposited with a suitable binder on to a thin melinex film to a density of about $35 \mathrm{mg} \mathrm{per} \mathrm{cm}^{2}$. The 'Owl Eye' system was then focused on this screen, viewing for reasons of radiation safety in a mirror set at $45^{\circ}$. Preliminary focusing was done with the X-ray set switched off and the room dimmed.

With the laboratory blacked out a bright image of the copper $K_{\alpha}$ reflexions from the (111) and (200) crystal planes of the copper specimen was readily obtained, the copper $\mathrm{K}_{\beta}$ reflexion from the (111) plane being just discernible. Using HP4 film developed in Microphen developer, and a $35 \mathrm{~mm}$ camera set at $\mathrm{f} 2.0$, a well balanced photographic negative was obtained in $1 / 30 \mathrm{~s}$. A print of such an exposure is shown in Fig. 1 compared with a similar print taken from a direct X-ray exposure made on fast dental film in $30 \mathrm{~s}$. Loss of detail is obvious, but this detracts only slightly from the value of the result as an effective brief time record.

With exposures of $1 / 30 \mathrm{~s}$, the frame-by-frame recording by cine-camera of a sequence of short-lived crystallographic events becomes possible.

G. TODD

M. P. TASKER

$R A R D E$,

Fort Halstead,

Sevenoaks, Kent

Received February 29, 1972.

${ }^{1}$ Chester, A. N., and Koch, F. B., Adv. X-ray Anal., 12, 165 (1969).

2 Callahan, J. M., Automotive Industries, April 1, 1970.

\section{Perfluoropolyether - a Vacuum Pump Fluid resistant to Electron Induced Polymerization}

GROWTH of polymer films on the components of electron beam instruments is a problem experienced widely because of the extensive use of oil pumps on such apparatus. Recently, new thermally stable fluids have become available which are based 